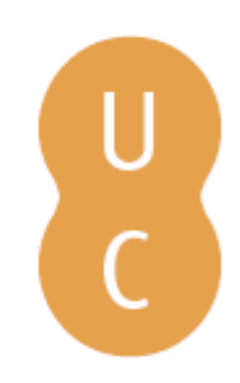

\title{
pompalina
}

\section{Luiz Carrisso e depois: museus, 'ciências coloniais' e a 'ocupação científica' das colónias}

\author{
Autor(es): $\quad$ Porto, Nuno \\ Publicado por: Imprensa da Universidade de Coimbra \\ URL \\ persistente: URI:http://hdl.handle.net/10316.2/32507 \\ DOI: $\quad$ DOI:http://dx.doi.org/10.14195/978-989-26-0363-6_5 \\ Accessed : $\quad$ 26-Apr-2023 15:56:12
}

A navegação consulta e descarregamento dos títulos inseridos nas Bibliotecas Digitais UC Digitalis, UC Pombalina e UC Impactum, pressupõem a aceitação plena e sem reservas dos Termos e Condições de Uso destas Bibliotecas Digitais, disponíveis em https://digitalis.uc.pt/pt-pt/termos.

Conforme exposto nos referidos Termos e Condições de Uso, o descarregamento de títulos de acesso restrito requer uma licença válida de autorização devendo o utilizador aceder ao(s) documento(s) a partir de um endereço de IP da instituição detentora da supramencionada licença.

Ao utilizador é apenas permitido o descarregamento para uso pessoal, pelo que o emprego do(s) título(s) descarregado(s) para outro fim, designadamente comercial, carece de autorização do respetivo autor ou editor da obra.

Na medida em que todas as obras da UC Digitalis se encontram protegidas pelo Código do Direito de Autor e Direitos Conexos e demais legislação aplicável, toda a cópia, parcial ou total, deste documento, nos casos em que é legalmente admitida, deverá conter ou fazer-se acompanhar por este aviso.

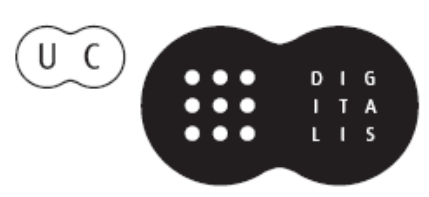




\section{HELENA FREITAS PAULO AMARAL ALEXANDRE RAMIRES FÁTIMA SALES \\ Coordenaçã̃o}

\section{Missão}

\section{Botânica}

Angola

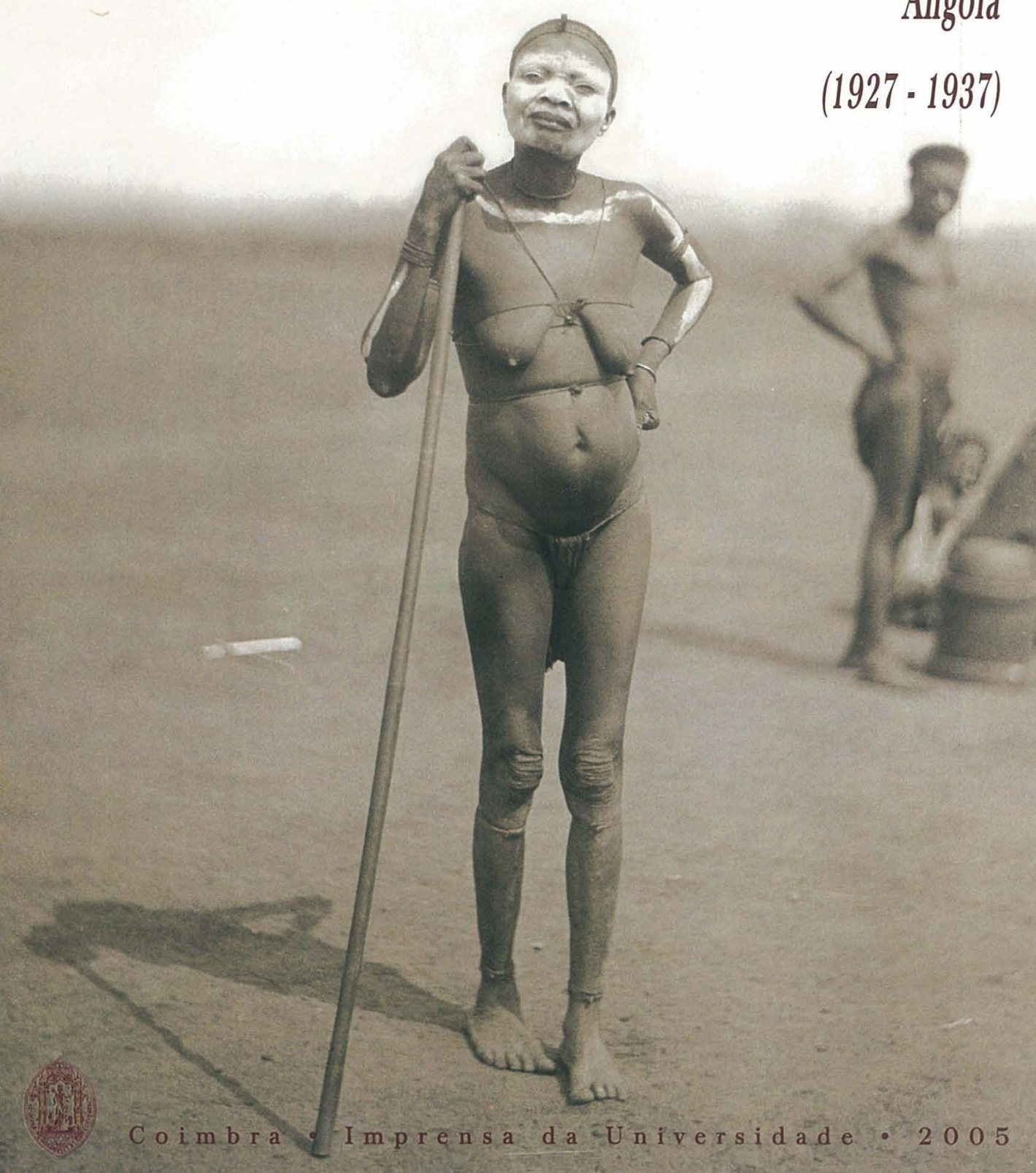


COORDENAÇÃO EDITORIAL

Imprensa da Universidade de Coimbra

\section{Edição de Imagem}

Paulo Amaral

Alexandre Ramires

\section{ConcepÇÃo GráficA \\ António Barros}

\section{PaginaCĩo}

António Resende

[Universidade de Coimbra]

\section{EXECUÇÃO GRÁFICA}

Imprensa de Coimbra, Lda.

Largo de S. Salvador, 1-3

3000-372 Coimbra

\section{Foto DA CAPA}

Mulher indígena.

Os traços brancos sobre o corpo são sinal de luto por morte do soba a quem ela pertencia.

Posto do Nordeste (Lunda), Julho 1927

ISBN

972-8704-41-0

DEPOSITO LEGAL

$223714 / 05$

(C) Fevereiro 2005, Imprensa da Universidade de Coimbra

OBRA PUBLICADA COM O PATROCÍNIO DE: 
helena freitas

Paulo AMaral

ALEXANDRE RAMIRES

FÁtima SALES

Coordenação

Missão Botânica

Angola 1927-1937

Coimbra - Imprensa da Universidade 

Nuno Porto

Departamento de Antropologia FCTUC

Museu Antropológico da Universidade de Coimbra

\section{Luiz Carrisso E Depois: Museus, 'Ciências Coloniais' E A 'OCUPAÇÃo CIENTÍFICA' DAS COLÓNIAS}

"Com o decorrer dos anos, a nossa investigação científica colonial, em lugar de se desenvolver e ampliar segundo o ritmo das outras nações coloniais, tem-se sucessivamente restringido, e hoje é insignificante, pelo menos nalguns ramos do conhecimento humano".

Carrisso, L.W., 1934, «Ocupação Científica das Colónias Portuguesas», Edições da 1. Exposição Colonial Portuguesa

O período em que decorrem as Missões Botânicas a Angola, presididas pelo Prof. Luiz Carrisso, constitui-se numa arena de debate sobre as relações entre o conhecimento científico e o desenvolvimento nacional, em particular, no que concerne o desenvolvimento das colónias. Este debate interno é tributário da evolução doutrinária internacional relativamente aos princípios de legitimação da ocupação de territórios coloniais por parte de Estados europeus, que entre a Conferência de Berlim (1884-1885) e a Conferência de Versalhes (1920) na sequência da guerra de 1914-1918, evolui de um princípio das relações históricas (um 'direito do primeiro chegado') para um princípio de 'ocupação efectiva' designadamente, a nível administrativo. No período entre guerras esboça-se um novo princípio de legitimação da posse de colónias baseado na 'ocupação científica' e este, por sua vez, enquadra-se, em Portugal, num debate que articula as dissenções sobre o projecto colonial com as valências políticas do conhecimento científico e, ambas, com políticas de institucionalização do trabalho científico e programas de promoção pública da ciência. 
A expressão 'ciências coloniais' explicita esta dimensão política do trabalho científico que emerge em articulação directa com a imaginação da nação como nação imperial. Sendo certo que esta é a versão da identidade nacional acentuada com a instauração do Estado Novo ela decorre, quer no ideário quer nas práticas sociais da sua difusão, de uma duração que lhe é anterior. O presente texto pretende contribuir para um enquadramento do trabalho de Luiz Carrisso neste período, orientando o inquérito para um instituto situado no cruzamento dos interesses em jogo - o museu - e um objecto nele produzido - 'a ciência colonial'.

\section{Comemorações e Congressos: a ciência entre a Fantasia e o Arquivo}

As Comemorações Nacionais e os Congressos usualmente associados às primeiras - susceptíveis de entendimento sob as metáforas da fantasia e do arquivo - constituem duas práticas exercidas no Estado Novo que lhe são anteriores, afinadas, de facto, nos finais do séc. XIX por partidários da República. Desde as comemorações centradas na figura de Camões (1880) que elas denotam duas características que acabam por se instalar nas práticas comemorativas como centrais na justificação que delas é feita pelos seus organizadores: por um lado, pretendendo produzir uma nova memória nacional a partir de temas culturais, é sua intenção programática deixar 'obra feita': às manifestações festivas e mais popularizantes associa-se uma componente erudita, relevada na publicação de estudos, conferências, saraus culturais, exposições temporárias ou mesmo duradouras (e.g. o Aquário Vasco da Gama), cujas actividades e publicações constituiriam material para o progresso do conhecimento. Por outro lado, esta programação do Arquivo, parece ser sistematicamente mitigada por um triunfo da Fantasia pelo que, desde o início deste ciclo comemorativo - Nacionalista-Imperial na designação de Catroga (cf. 1998) - as manifestações popularizantes são tornadas centrais nos programas comemorativos.

O caso da comemoração de Camões é um exemplo desta tendência. Com o aval da Sociedade de Geografia de Lisboa, da Academia de Ciências de Lisboa, da Universidade de Coimbra e da Coroa, as celebrações vividas em ambiente metaforicamente descrito como sendo de religiosidade (marcada pelas expressões de procissão ou romagem) - enveredam pela construção de uma hagiografia cívica, exemplificada na transladação dos restos mortais de Camões para o Mosteiro dos Jerónimos, por sua vez, 
equiparado a Panteão Nacional. Associado a este facto, as comemorações são uma celebração da nação através do seu Império e, neste sentido:

«(...) não eram somente os descobrimentos que se homenageavam mas também a própria colonização, significada [no Cortejo Histórico integrado no programa de festas] por um carro alegórico dedicado às Colónias" (cf. idem: 229).

Tratava-se, num ambiente de tensão entre os republicanos e a Monarquia Constitucional, de encontrar um ponto de concordância dotado, de um e do outro lado, de uma base 'nacional', base essa que é condensada na ideia segundo a qual:

«(...) Portugal, apesar da situação em que se encontrava no contexto dos novos impérios, ainda podia ter uma grande missão a cumprir desde que soubesse extrair do passado o exemplo para as grandes tarefas do futuro» (cf. idem).

As comemorações Henriquinas de 1894, por ocasião da passagem do centenário do nascimento do Infante, retomam a questão colonial, recentrada como questão nacional na sequência do Ultimatum (1890), e constituindo - na sequência da revolta Republicana de 31 de Janeiro no Porto - um meio de conciliação dos portugueses com a monarquia. As comemorações tiveram lugar no Porto e tal como as comemorações camonianas, cujo programa apresentava um recorte positivista, as comemorações Henriquinas promovem, para além de conferências e do concurso literário, uma exposição industrial e colonial - de que resulta o acréscimo das colecções etnográficas do Museu Antropológico da Universidade de Coimbra - um cortejo cívico, uma festa fluvial e o lançamento de uma estátua (cf. idem: 233). O propósito declarado das comemorações, foi o apelo à comparticipação colectiva, em função do qual:

«(...) tudo foi mobilizado para transformar as festas numa lição móvel de história que, pelo menos momentaneamente, recalcasse a consciência decadentista e criasse a ilusão de que estava para breve a chegada de um novo período de grandeza» (idem: 235, itálicos no original). 
São ainda preocupações desta índole que estarão presentes nas comemorações do Centenário da Índia (1897-1898) propostas pela S.G.L., que acabam por se materializar num programa mais popular e menos ambicioso que o inicialmente previsto e tendo como novidades, relativamente aos programas das comemorações anteriores, a criação de um aquário permanente - o Aquário Vasco da Gama inaugurado em Maio de 1898 - e uma seç̧ão colonial com 'exibição viva de tipos indígenas das colónias portuguesas' (idem: 24.0). Note-se que neste momento deste ciclo nacionalista-imperial, as comemorações pretendem fazer chegar os seus resultados a interlocutores estrangeiros. Desde a celebração camoniana, a S.G.L. patrocinara as expedições políticas e científicas de Henrique de Carvalho 1884-1887 à Lunda e as de Hermenegildo Capelo e Roberto Ivens da costa ocidental à costa oriental de África (1884-1885); na sequência da Conferência de Berlim e da doutrina da "ocupação efectiva» na legitimação da dominação colonial, as campanhas militares de Paiva Couceiro (1890, 1891, 1895) e de Mouzinho de Albuquerque (1895-1898) haviam produzido um consenso nacional sobre a afirmação da capacidade dos portugueses na matéria colonial. $\Lambda$ os direitos históricos reclamados por Portugal (e liminarmente postos de lado com o Ultimatum) juntavam-se agora os direitos de ocupação efectiva. Consequentemente, procurava-se sublinhar o carácter pioneiro dos portugueses na descoberta e exploração de territórios ultramarinos em função do qual se reclamava para Portugal um lugar igualmente pioneiro no progresso da humanidade e se contestavam, embora de forma indirecta, as críticas à colonização portuguesa e a prevalência dos direitos acordados em Berlim sobre os direitos históricos. Os elementos de continuidade neste ciclo comemorativo são, em suma, a reivindicação: gal na construção da modernidade e da atribuição de um estatuto especial ao Brasil - prova póstuma das nossas virtudes civilizadoras - a intenção de combater a imagem negativa do país e da sua colonização (...) traduzida em exposições que se queriam ilustrativas dos progressos científico-técnicos e económicos, ou que eram montadas, de acordo com os paradigmas da época, para mostrar a especificidade étnica e anímica de um povo que, apesar de pequeno, deu novos mundos ao mundo" (idem: 241-242). 
Os centenários de Ceuta e de Afonso de Albuquerque (1915), celebrados já após a instauração da República, acrescentam ao quadro definido pela prática comemorativa havida até então uma contextualização que as refere à contemporaneidade da sua execução. A época obriga menos à comemoração do Império que a «(...) guerrear para o defender, defendendo a própria República» (idem: 243). A ambiciosa proposta da Academia de Ciências de Lisboa - prevendo congressos internacionais e um sobre as 'Raças' - acaba, sob o fraco apoio de um estado em convulsões sucessivas (cf. Ramos 1994) - por se cingir a duas cerimónias solenes nas Academias de Ciências de Lisboa e do Porto e à edição de obras de estudo (cf. Catroga 1998: 244).

Até à emergência do Estado Novo em 1926, apenas o Centenário da Independência do Brasil (1922), a "Festa da Raça», associada ao Centenário do Nascimento de Vasco da Gama (1924) e o 4. ${ }^{\circ}$ Centenário da sua morte (também em 1924) constituirão motivos comemorativos, numa fase em que as próprias comemorações se tornam terrenos de contestação, dado fracasso que representavam face à promessa republicana de regeneração nacional. Na preocupação de raiz positivista de constituição de uma hagiografia cívica, tinha-se criado a noção - errada, segundo António Sérgio - de acordo com a qual os Descobrimentos haviam resultado mais da acção de grandes homens que de «séculos de esforço metódico e persistente, de inteligência e complexa organização, de estudo exaustivo de um dado problema feito por uma elite nacional» (Sérgio in idem: 250).

A importância da "questão colonial», agudizada pelo relatório Ross de 1925, secundarizava iniciativas entretanto surgidas de celebração da Fundação de Portugal e da Restauração, assim como dos seus heróis, em particular de D. Nuno Álvares Pereira, canonizado em 1918. A celebração dos Descobrimentos actuava como uma espécie de 'rito de refundação' (Catroga 1998: 255), suscitando suficiente interesse público de molde a propiciar, mesmo no âmbito comemorativo, uma historiografia de carácter mais crítico. Não obstante, na sequência do relatório Ross, a S.G.L. apoia a constituição de uma Comissão de Defesa das Colónias, ao qual o grupo da Seara Nova adere na sua quase totalidade em conformidade com a noção - que apenas excluía do consenso sectores internacionalistas - segundo a qual a identidade nacional depende da integridade do Império (cf. idem: 257). 


\section{O Estado Novo}

As celebrações do Estado Novo inscrevem-se na continuidade deste ciclo, vindo a acentuar a tendência de associação e justaposição entre a Fundação, os Descobrimentos e o renascimento do Estado Novo, patentes quer na celebração emblemática do período áureo do Salazarismo, que foi a Exposição do Mundo Português (1940), quer na Exposição Colonial do Porto (1934), em cujos congressos Luiz Carrisso intervém. Na sequência do golpe de estado de 28 de Maio de 1926, o percurso seguido a este propósito, parece consistir numa regularização e institucionalização de iniciativas avulsas - por exemplo, mediante o estabelecimento da ciclicidade anual das Semanas das Colónias na S.G.L. a partir de 1927 - e uma correlativa racionalização da administração da ideia de Império quer através de organismos dedicados à divulgação e estudo de assuntos coloniais quer ainda através do esforço legislativo. Nas palavras de Catroga, «(...) o salazarismo intensificou campanhas tendentes a levar os portugueses não tanto a África, mas sim à 'redescoberta' do mito da grandeza imperial (...)» (idem: 258).

A Exposição Colonial do Porto, de 1934, pode ser entendida como a primeira dramatização dessa 'redescoberta', patenteando a articulação de um conjunto de dispositivos susceptíveis de tornar a questão colonial e a questão nacional não apenas indissociáveis, mas, além disso, transversais a diferentes campos de actuação institucional.

\section{A Exposição Colonial do Porto}

Segundo o Comissário da Exposição, Henrique Galvão, a primeira Exposição Colonial Portuguesa - proporcionando uma 'viagem pelo Império,

132 no Porto', teria constituído um processo espiritual de cariz pedagógico ao fornecer aos portugueses informações e imagens sobre as colónias e a acção portuguesa nelas desenvolvida (cf. Thomaz 1997: 159). O seu dispositivo mais durável na memória colectiva, terá sido a instalação expositiva de 324 nativos, com os quais se criou, nos jardins anexos ao Pavilhão das Colónias, um conjunto supostamente representativo da diversidade civilizacional e espacial do Império. Cabe notar que este dispositivo fora sendo consolidado no decurso do circuito de Exposições Coloniais e Internacionais inauguradas em 1851 com a Exposição de Londres, após a sua estreia num 
contexto de representação da diversidade popular interna, na Suécia. Mas faz enorme sucesso no Porto em 1934, chegando mesmo a cunhar, como alternativa a 'visitar a Exposição', a expressão 'ir ver os pretos' (idem: 174). Mesmo em Portugal, o dispositivo fora já ensaiado em Lisboa, dois anos antes, aquando da Exposição Industrial de Lisboa (cf. idem: 159), após ter tido a sua estreia nas comemorações do $4 .{ }^{\circ}$ Centenário de vasco da Gama em 1898. Na imediação - em termos espaciais, ou na sequência - em termos do roteiro da visita, do Pavilhão das Colónias - onde toda a obra colonial portuguesa era tornada em espectáculo - este contingente constituía uma espécie de testemunho vivo do que ali perto, no Pavilhão, se expunha: um ideal de congregação de todos os portugueses em torno do ideal da nação, que mostrava estes como portugueses de outras raças que também comungavam do «renascimento imperial» advogado pelo Ministro das Colónias, Armindo Monteiro. Dividida em dois espaços, um dedicado à iniciativa do Estado, outro dedicado à iniciativa privada, a novidade da E.C.P. consiste nesta apresentação total da entidade espiritual renascida com o projecto imperial do Estado Novo.

Em termos legislativos, essa entidade fora materializada na Constituição promulgada no ano anterior, que consagrava o Acto Colonial de 1930, no qual as colónias haviam sido integradas na 'essência orgânica da nação portuguesa'. O próprio Comissário se encarrega de estabelecer esta relação quando escreve:

«Depois do Acto Colonial (...) era realmente necessária uma grande manifestação, clara e exuberante, que transmitindo à nação o conhecimento e o amor das causas, viesse a oferecer ao governo, através duma opinião e dum pensamento colonial formados, apoio consciente para a obra realizada e para tudo o que ainda falta alcançar» (in idem: 163, n16).

Como visualização deste projecto de imaginação do futuro, a ideografia do Império é justaposta à da metrópole mostrando, quer na língua creditada como franca desse espaço imaginado - i.e. a portuguesa - quer em inglês, numa clara atenção ao olhar estrangeiro, que «Portugal não é um País Pequeno». Com sua área total de $2.171 .713,81 \mathrm{~km} 2$, era visualizado como maior que o espaço europeu em que fora sobreposto, já que a Espanha, França, Inglaterra, Itália e Alemanha não ultrapassavam os $2.096 .639 \mathrm{~km} 2$. 
$\Lambda$ E.C.P. é, enquanto exposição, uma materialização de um exercício de coordenação e centralização que vinha sendo feito noutros domínios com «(...) a institucionalização jurídico-política (Acto Colonial 1930; Constituição 1933), social (legislação sobre o corporativismo) e repressiva (P.V.D.E., e reorganização da censura)" (Catroga 1998: 260). Neste âmbito se levara a cabo a reforma da Agência Geral das Colónias em 1932, a criação do Secretariado de Propaganda e Informação (depois Secretariado Nacional de Informação) em 1933.

Um segundo elemento deste propósito totalizante presente na E.C.P., consiste na congregação de iniciativas dedicadas a públicos específicos, preconizando uma participação estruturada de todos os grupos sociais, incluindo as elites intelectuais. A festa surge, assim, assessorada pela ciência, manifesta sob a forma de Congressos. É nas respectivas sessões que é renovada alguma atenção aos museus, no âmbito da articulação - com o público não especializado - do conhecimento produzido sobre as colónias.

No I Congresso Nacional de Antropologia Colonial, realizado no Porto por ocasião da E.C.P., a questão da criação de um Museu Etnográfico e Colonial é trazido à liça por dois congressistas, o Tenente Afonso do Paço e Luís Chaves, etnógrafo do Museu Leite de Vasconcelos de Belém. Para o primeiro a criação de tal instituto é um imperativo nacional:

«Trabalhamos hoje, afincadamente no ressurgimento do Império, a tuba da fama esforça-se por mostrar ao mundo a nossa actividade colonizadora, mas ainda não cuidamos a sério da organização de um museu de etnografia ultramarina digno da terceira potência colonial, assim como não temos um bom museu de etnografia metropolitana» (Paço 1934: 24).

A proposta de Afonso do Paço articula dois interesses distintos, senão mesmo díspares. Um primeiro refere-se à função de representação que o museu assumiria, no contexto internacional, pelo que se reporta à recente conversão do Museu do Trocadéro, em Paris, por ocasião da Exposição Colonial de 1931, sob a orientação de Paul Rivet (cf. Dias 1991), que caracteriza mataforicamente como uma «Fénix renascida» (cf. Paço 1934: 25). Para o proponente, à ausência do museu parece corresponder uma demoção do $3 .^{\circ}$ lugar na ocupação colonial, cuja rectificação, por esta via procurada, é urgente. Um segundo interesse reveste-se de uma natureza mais 
complexa porquanto, na proposta aqui formulada, esse museu já existe, em sede da Sociedade de Geografia de Lisboa, «(...) uma entidade particular a quem o Estado muito deve. Haverá portanto necessidade de negociações, de resolver determinadas dificuldades» (idem: 25). Recorda, a este propósito, o proponente, que «São as suas colecções que figuram em exposições coloniais dentro e fora de fronteiras» (idem: 26). E, no final, visando uma solução de compromisso, a sua proposta resume-se a um Museu de Etnografia, do continente e das colónias, para o qual prevê uma resolução urgente:

«Delineadas as bases em que um Museu de Etnografia devia assentar, pensar-se-ia também na recolha de objectos, fotografias, filmes documentários, discos com canções, organização de questionários, mesmo em missões científicas, enfim, mil e uma coisas necessárias à vida do museu e que seria longo aqui enumerar. É que o tempo urge; a onda de civilização e modernismo que dos grandes centros transborda pelos campos e sertões em breve destruirá tudo o que de típico ainda existe» (idem).

À proposta de Afonso do Paço, cujo cariz pragmático surge objectivado na consagração implícita do Museu da S.G.L. como museu nacional, uma vez negociadas as dificuldades advindas da sua execução, pode contraporse a proposta de Luís Chaves, que prevê a constituição de raiz de um novo museu, assumidamente alinhado pelo ideário nacionalista-imperial do Estado Novo. O seu Museu Etnográfico do Império Português é definido como instrumento de uma política historicamente provada e cuja continuidade constitui, para ele, matéria de facto. Simultaneamente memorial, mnemónica para o futuro e sinédoque do Império, o programa do museu é justificado nos seguintes termos:

«Ninguém porá em dúvida esta verdade: Portugal tem a obrigação histórica e a necessidade política inadiável de organizar o museu etnográfico do seu império.

O Primeiro povo que devassou os mares e colonizou com o seu sangue, com a sua alma e com a sua fé, terras de todos os continentes, ainda não tem o museu que merece o esforço dos antepassados e é devido à dedicação dos actuais continuadores da obra civilizadora dos portugueses. 
$\mathrm{Na}$ construção do Nacionalismo inteligente, rota espiritual em que caminhamos, impõe-se o museu do Império Português, como demonstração de quanto fomos, prova de quanto somos e alto farol do que devemos ser.

(...)

A quem desconheça Portugal, mostre-se-lhe o museu. A quem desconheça a obra dos Portugueses, ontem e hoje, o que foi e o que é, mostre-se-lhe o museu» (Chaves 1934: 28).

As seis secções que organizam as colecções do Museu Etnográfico do Império Português - incluindo nelas um Vestíbulo sinóptico - são comentadas por versos seleccionados de Camões submetendo a sua distribuição geográfica (Europa Continental e Insular; África, Ásia, Oceânia e América) a uma interpretação historicista, mitográfica mesmo, pontuada por projecções ideográficas do Império nas suas vertentes contemporâneas e históricas, relativas quer à geografia política quer humana, pela monumentalização dos intérpretes históricos das conquistas e ocupações e pelo comentário, nos versos de Camões, mostrando o Império como destino nacional.

A título de exemplo, registe-se que, neste projecto, a $2{ }^{\text {a }}$ Secção, relativa a África, seria - à semelhança das restantes - introduzida pelas lápides camonianas. Primeiro gerais "De África tem marítimos assentos (Camões, Lus. VII, 14) ... também nos conta dos rodeios / Longos em que traz o mar irado, / Vendo os costumes barbaros alheios, / Que a nossa Africa ruda tem criado. (Camões, Lus., II, 110)» (in Chaves 1934: 35). Depois particulares a cada um dos territórios. Seguem-se, no projecto, os mapas, nesta secção distribuem-se da seguinte forma:

«a) África portuguesa: mapa histórico;

b) África portuguesa: mapa político;

136

c) Cabo-Verde: político; físico, em relevo;

d) Guiné: político; etnológico; físico, em relevo;

e) S.Tomé e Príncipe: político; etnológico; físico, em relevo;

f) Angola: político; etnológico; físico, em relevo;

g) Moçambique: político; etnológico; físico, em relevo;

h) África Portuguesa: produtos característicos de cada província» (idem: 36).

Seguem-se aos mapas as "Cenas figuradas ao vivo com manequins [sic]; por províncias» (idem), distribuídas por: "vida doméstica, habitações, 
aldeamentos; vida agrícola e labor industrial; assuntos guerreiros; dança e música; assuntos religiosos e de magia» (cf. idem). Por contraponto, suceder-se-lhes-iam as "Cenas da vida das missões e das guarnições militares»; as «Séries de objectos de fabrico e uso dos indígenas por secções e por província» e Estátuas:

"África, Adamastor, a Raça Preta, cada província representada por figura própria, escolhida entre heróis indígenas ao serviço de Portugal, ou de indígenas dominantes e prestáveis; Gil Eanes, Diogo Cão, Bartolomeu Dias, Pero de Alenquer, Tristão da Cunha, Duarte Lopes, Salvador Correia de Sá; António Enes, Mousinho, D. António Barroso...» (idem: 37).

A revelação cognitiva, certamente concebida como pedagógica e formativa, é intrinsecamente uma revelação histórica e nacionalista, que faz do projecto do Museu Etnográfico do Império Português, um lugar de memória, segundo a expressão de Nora (cf. 1992). A persistência dos materiais ideográficos é consonante com a negação da menoridade europeia do país, quer geográfica quer política, que a ideografia declaradamente conceptual de Henrique Galvão sublinhava pela negação que dava a ver. Esta proposta estabelece-se na continuidade do mote da E.C.P., mas tal como a Exposição - que terminará em setembro de trinta e quatro - e como a proposta pragmática de Afonso do Paço, também esta servirá apenas para lustro das publicações do Congresso, acabando por engrossar a fileira dos projectos não executados.

\section{A Exposição do Mundo Português}

Cabe notar que a formulação periódica de propostas para a criação de um museu colonial ou imperial, é enquadrada numa configuração de debate público - embora matizado pelo autoritarismo do Estado - sobre a questão colonial, presidida pela articulação desta questão com a problematização do lugar que nelas seria reservado ao conhecimento científico e a prospecção dos modos da sua institucionalização. Recorde-se, neste âmbito, a realização do II Congresso Colonial em 1923 na S.G.L. (o primeiro fora em 1901), o início das Semanas das Colónias, também na S.G.L., a 
partir de 1927; em 1930 o III Congresso Colonial Nacional, ainda na S.G.L., e em 1933 a Conferência Imperial Colonial; em 1934, associadas à Exposição Colonial do Porto, além do já referido I Congresso de Antropologia Colonial, realizam-se ainda: o I Congresso da União Nacional, o Congresso Militar Colonial e o I Congresso de Intercâmbio com as Colónias; em 1936 iniciam-se as Conferências de Alta Cultura Colonial; tem lugar, ainda este ano, a I Conferência Económica do Império Colonial Português; no ano seguinte, por ocasião da Exposição Histórica da Ocupação, decorre o I Congresso de História da Expansão Portuguesa no Mundo; em 1940, distribuídos por Coimbra, Lisboa e Porto, decorrem os Congressos do Mundo Português. No plano administrativo, em 1924, por extinção das Agências de Angola e de Moçambique, é criada a Agência Geral das Colónias; em 1931 é criado o Arquivo de História Colonial (depois Histórico Ultramarino); em 1936 é criado o Instituto de Alta Cultura (por reforma da Junta Nacional de Educação) e a Junta das Missões Geográficas e Investigações Coloniais que, entre outras atribuições, tomará sob tutela a coordenação de missões científicas nas colónias, institucionalizando uma prática incipiente e desprovida de articulação.

De facto, até à data da fundação da J.M.G.I.C., têm lugar missões científicas de diversas filiações institucionais: da Escola de Medicina Tropical (1901, Missão para o Estudo da doença do sono em Angola; 1904, Missão a S. Tomé e Angola, para estudo do béri-béri e prosseguimento do estudo da doença do sono; 1907, Missão à Ilha do Príncipe, doença do sono; 1911, Missão Ilha do Príncipe (1911-1914), doença do sono; 1927, Missão a Moçambique, doença do sono; 1932, Missão à Guiné Portuguesa, doença do sono e suas particularidades (cf. Azevedo 1958: 25-27)). Executadas por comissões de nomeação governamental, em 1929 a Missão Hidrográfica de Moçambique e em 1932 a Missão Geográfica de Moçambique. Sob financiamento da Junta de Educação Nacional, depois instituto de Alta Cultura, em 1934 a $1^{\underline{a}}$ Missão Antropológica a África (Angola, Dembos, António Almeida); em 1936, a $1^{\text {a }}$ Missão Antropológica de Moçambique (J.A. Santos Júnior; org. Instituto de Antropologia da Faculdade de Ciências da Universidade do Porto, integrada na referida Missão Geográfica de Moçambique). Ainda em 1936, a Missão Hidrográfica de Angola, em 1937, a Missão Botânica de Angola; de 1936 a 1938 a Missão da Carta Magnética de Angola e, em 1938 a Missão Geográfica de Timor (cf. Santos Júnior 1944: 2). 
Esta prática descontínua reflecte a relativa marginalidade do trabalho científico no processo colonial, em particular no que concerne o ensino. Nesta área, recorde-se que apenas duas instituições se dedicam exclusivamente à produção e reprodução do saber colonial: a Escola Superior Colonial associada à S.G.L., fundada em 1906 - sucessivamente reformada em termos curriculares em 1919, 1926 e 1946, até à sua maior reestruturação em 1954 com a passagem a Instituto Superior de Estudos Ultramarinos (cf. Thomaz 1997: 74-80) - e a Escola de Medicina Tropical, fundada em 1902 (D.L. 4/(04/1902), que centraliza o ensino médico previamente ministrado na Escola Médica e Hospital da Marinha e que passa, em 1935, a Instituto de Medicina Tropical (D.L. 1920 de 29/05/ 1935). E, enfim, desprovido deste carácter de exclusividade, registe-se o Museu Agrícola Colonial, instalado no perímetro de Jardim Colonial em Belém. Inaugurado em 1929 este Museu-Laboratório está associado ao Instituto Superior de $\Lambda$ gronomia e tem por objectivo a divulgação de:

"(...) conhecimentos sobre a origem, preparação tecnológica, composição química, valor, aplicação e importância económica dos produtos agrícolas e florestais das colónias portuguesas, bem como daqueles que procedam das colónias estrangeiras e países quentes, cuja produção convenha estabelecer nas nossas colónias» (B.A.G.C. 1929: 117-118).

O renascimento nacional sob a égide do Estado Novo, cuja apoteose festiva seria objectivada na Exposição do Mundo Português, parece criar expectativas nalguns congressistas, de uma correlativa afirmação de uma política colonial alinhada com uma atitude científica que se materializaria numa institucionalização das ciências coloniais. Essas expectativas são tanto mais legítimas quanto o Ministro das Colónias em exercício, Francisco Vieira Machado, será o principal mentor e executante de uma política imperial que procura integrar num mesmo espaço económico e cultural a metrópole e as colónias, política essa que será materializada quer em iniciativas de divulgação e investigação colonial na metrópole - e.g. os congressos, comemorações e exposiçòes - quer em institutos administrativos, designadamente, na criação da Direcção Geral do Ensino Colonial. Dado tratar-se de uma política de centralização e articulação interna do espaço do império, ela supõe uma base de conhecimento das questões 
coloniais, em particular, as que se relacionam com a racionalização económica desse espaço, que seria preferencialmente obtida por uma política informada pelas necessidades científicas dela decorrentes. É neste quadro que uma visão crítica do 'estado da nação', nesse capítulo, é claramente expressa por alguns congressistas provenientes de diferentes quadrantes de actividade, não deixando de apontar possíveis soluções pois também para tal serviam os Congressos.

O teor das propostas diverge, mas em 1940 diagnosticam a ausência de articulação entre as diferentes iniciativas e organismos, prevendo, por vezes, entre outras soluções de coordenação, a criação de museus. João F. Rodrigues, diplomado pela E.S.C., e experiente colonial, soluciona a questão com a criação de um Instituto Colonial:

«(...) não vemos as instituições de cultura e ensino superior colonial (Instituto de Medicina Tropical; Escola Superior Colonial; Agência Geral das Colónias; Arquivo Histórico Colonial; Museu Agrícola Colonial; Sociedade de Geografia) nem os que têm acolhido e realizado embora a eles propriamente se não destinassem (Faculdade de Letras, de Direito e de Ciências e Instituto Superior de Agronomia e de Ciências Económicas e Financeiras de Lisboa; Faculdade de Direito e de Ciências de Coimbra, Faculdade de Ciências do Porto) não vemos, dizíamos, que haja a coordenação necessária dos seus esforços. E só, afinal, desta cooperação pode resultar obra inteiramente profícua.

$\Lambda$ ssim, a par de uma coordenação de ensino no Instituto Colonial, que pressupomos criado por tão necessário se tornar, é de absoluta necessidade uma coordenação da investigação científica de que ele será o melhor promotor, mas não o único realizador» (Rodrigues 1940: 71).

Ao Instituto deveria estar associado um Museu, pelo qual se realizaria a coincidência entre os propósitos de constituição de uma ciência colonial e a divulgação junto do público metropolitano, de uma cultura colonial (cf. idem: 66). Neste particular, segue as recomendaçòes anteriormente esboçadas por outro congressista, o Prof. Celestino da Costa, Presidente do Instituto de $\Lambda$ lta Cultura. Este, após rever exaustivamente o panorama das 
instituições científicas coloniais no Império Britânico, nas Colónias Francesas, Belgas, Holandesas e Italianas, conclui da seguinte forma a sua comunicação ao Congresso:

"Conforme os seus recursos, a importância das colónias, o grau de civilização do País colonial, assim essas instituições científicas ultramarinas são mais ou menos importantes. Mas existem e umas são os observatórios meteorológicos e astronómicos, outras os museus de história natural e os jardins botânicos, outras os laboratórios de bacteriologia, de higiene, de parasitologia, de entomologia, de patologia tropical humana e veterinária, de agronomia aplicada, etc. Grande é a variedade dessas instituições e das soluções adoptadas. Diversas são também as formas de colaboração no estudo científico das colónias dos orçamentos metropolitanos e coloniais. Mas todos os países coloniais cultos sentem a importância do problema, vêm os olhos dos outros povos postos nas suas colónias e não se poupam a esforços para empreenderem eles próprios os seus estudos e não dependerem para tal do estrangeiro. Assim se defendem também as colónias» (Costa 1940: 98).

A perspectiva urgente de uma reforma é largamente justificada pela conjuntura internacional:

"Nesta hora que está passando é de supor-se que a distribuição dos territórios ultramarinos sofrerá grandes alterações e que alguns dos dados que vão seguir-se serão brevemente inactuais. Representam apenas a situação tal qual era antes da guerra e darão uma ideia do que cada país tem feito e de que forma organizou a investigação científica nas suas colónias. Nestas informações poderemos nós portugueses colher elementos úteis e estímulos» (idem: 84).

A questão é, nesta perspectiva, inteiramente estratégica: após a guerra, o mapa colonial será redesenhado e a melhor forma de Portugal manter os territórios que ocupa é demonstrando que o faz cientificamente. Na arena internacional, a ciência não é, nem apenas, nem sobretudo, conhecimento, mas uma arma política. A solução, contudo, é interna. E o panorama interno não é dos melhores. Para o Professor de Medicina Santa-Rita: 
«Em relação à actividade científica do país, o balanço respeitante às colónias não é desanimador, se atendermos a que, como se vê, data, em verdade, de poucos anos o reatar do interesse científico pelas colónias, mas apresenta graves deficiências no que respeita à orientação, direcção e continuidade.(...) O incentivo oficial tem sido escasso, descontínuo e até, por vezes,(...) em lugar de incentivos surgem entraves (...). Tem-se revelado a boa vontade de certos ministros ou dirigentes (...) mas como casos individuais e não como atitude da administração perante o problema» (Santa Rita 1940: 25-28).

Não é, pois, de estranhar, que sob este quadro algo pessimista, a proposta de um museu o apresente como instituição regenerativa de um processo político errado. Fora do programa do Congresso Colonial, o antropólogo do Porto, J. R. Santos Júnior advoga esta via argumentativa na sua proposta do Museu Colonial Português, proposta que articula com a já veiculada necessidade urgente de um Instituto Colonial, estabelecida por outro orador. Tal como os anteriores congressistas citados, a estratégia de Santos Júnior recorre ao interessamento dos agentes políticos para o campo científico, sublinhando o seu carácter cívico enquanto instituto de difusão de um ideal colonial que é, à época, um traço de definição da identidade do País tal como o Estado Novo a propunha, inscrevendo o museu no campo público então definido como o campo da 'ciência e cultura coloniais':

«É necessário acabar, por todas as formas, com as opiniões erradas que mesmo entre indivíduos de certo grau de cultura, correm sobre as nossas possessões africanas tidas como terras inóspitas duma insalubridade aterradora.

O Museu Colonial Português contribuiria para que aqueles que o visitassem, levassem uma ideia justa da extraordinária facilidade de instalação e adaptação do branco na grande maioria das regiões das nossas colónias, especialmente de Angola e de Moçambique que, pela sua vastidão, são aquelas que carecem de maior número de portugueses da metrópole.

Em paralelo com o Museu Colonial Português existiria o Instituto Colonial, exclusivamente votado à investigação científica» (Santos Júnior 1940: 103). 
A proposta de Santos Júnior resulta de uma experiência algo sólida nesse domínio: enquanto investigador da Missão Antropológica a Moçambique (1936 e 1937), Santos Júnior tivera a oportunidade de trabalhar nalguns museus em África, designadamente no Museu do Cabo, no Museu de Pretória (na então União Sul Africana, de 1946 em diante República da África do Sul), no Museu provincial Álvaro de Castro em Lourenço Marques, no Museu de Bulawayo e no Museu de Salisbury, na Rodésia do Sul (cf. Santos Júnior 1944: 8-9). Entre Novembro e Dezembro de 1938, fora encarregue pelo Ministro das Colónias para uma missão de estudo de Museus Coloniais em França, Bélgica, Holanda e Alemanha (cf. idem: 15), e a comunicação apresentada ao Congresso, redigida - seguindo o formulário jurídico - em XII Bases, parece reportar-se a uma execução eminente, prevendo os diferentes tipos de público, de funcionários, de serviços internos, etc. Não obstante, quatro anos decorridos, a expectativa mantém-se (cf. idem).

O plano do Museu é definido na Base V, estando organizado em 4 secções: Secção de História (Descobrimento, Ocupação, Conquista); Secção de Etnografia, Secção de Ciências Naturais (Antropologia, Zoologia, Botânica, Mineralogia e Geologia); Secção de Produtos Coloniais, Economia Higiene. (cf. Santos Júnior 1940: 106-7). Em termos orgânicos, prevê o seu financiamento por cada uma das colónias, o envolvimento dos respectivos governos na «beneficiação dos serviços» (idem), assim como «a comparticipação valiosa dos funcionários coloniais, principalmente os do quadro administrativo e os missionários, para a aquisição de peças a enviar ao Museu Colonial» (idem: 108). Finalmente, a proposta é explicada como resultado de um «esforço patriótico», uma vez que:

"O Museu Colonial Português deverá ser escola onde se aprenda sem esforço e templo onde se entre com respeito.

Ali irão os portugueses em romagem do mais puro nacionalismo apreciar a grandeza e o esforço lusíada no Mundo e o valor dos seus heróis da guerra e da paz, atestado quer pela descoberta de novos mundos quer pela civilização de povos bárbaros e primitivos. (...)

O Museu Colonial será o grande Museu Português» (idem: 104-5).

J.R. Santos Júnior não estava só nesta crença assim expressada. Há claros indícios de um consenso crescente relativamente à edificação de um museu desta natureza, mas pode aventar-se a hipótese deste consenso não 
ter tido um público suficientemente alargado, pelo que, se a ideia parece ser consensual no seio de um grupo favorável a um 'colonialismo científico', a não criação do museu parece apontar para uma configuração social em que o tema é dissentâneo. De facto, o museu que vinga na sequência da Exposição do Mundo Português - o Museu de Arte Popular, inaugurado em 1948 - reflecte a posição de força do dirigente do Secretariado de Propaganda Nacional / Secretariado Nacional de Informação, António Ferro (cf. Paulo 1994: 118), e a crescente secundarização do grupo favorável ao 'colonialișmo científico'. Registe-se, a este propósito, que entre 1930 e 1940 se dá uma alteração significativa na política de propaganda que passa a fazer parte das funções do S.P.N. / S.N.I., numa lógica de centralização distribuída por outras actividades (e.g. o Concurso da Aldeia Mais Portuguesa, 1938-39) que conduzirá a inflexões quer no estilo quer no conteúdo das exposições internacionais seguintes - Exposição Internacional de Tripoli, 1935, Paris, 1937, Nova Iorque e S. Francisco em 1939 - e, finalmente, na exposição do Mundo Português para a qual é constituída uma comissão alargada (em que António Ferro acumula o cargo de secretário com o de responsável pela Propaganda (cf. Acciaiuioli 1998: 113)). Personalizando esta transformação política em António Ferro e Henrique Galvão, comissário da Secção Colonial da Exposição de 1940, estar-se-ia perante uma oposição entre um 'conto de fadas' do director do S.P.N., e um naturalismo exoticizante, que perderia perante aquele (cf. idem: 174). Manifestando um e outro correntes de opinião divergentes, por enquanto, no interior do Estado Novo, pode interpretar-se o adiamento do Museu Colonial, como um adiamento da questão no seu conjunto.

\section{A Ocupação Científica do Ultramar Português}

Deve, porém, ter-se em conta, que a realização do Congresso Colonial no âmbito dos Congressos do Mundo Português, ocorre num momento de reformulação da J.M.G.I.C. que será legislada em 194.5. Em fins de 194.1, o então Presidente da Junta, J. Bacellar Bebiano, envia ao Ministro o seu "Plano de investigação científica colonial», o qual, refira-se de passagem, incorpora várias das sugestões trazidas a lume pelos Congressistas, respondendo, designadamente, à preocupação com a coordenação e centralização das actividades de investigação. O Ministro, por sua vez, despacha o Plano pedindo parecer ao Ministro da Educação Nacional e ao Conselho do 
Império Colonial, acabando por ser aprovada a alteração legislativa em 194.5, ou seja, já sob o ministério de Marcelo Caetano na pasta das Colónias. No despacho ministerial de Vieira Machado, escreve-se:

«Deve-se elucidar o Ministério da Educação e o Conselho do Império da intenção do Ministério das Colónias de criar um Museu Colonial, anexo ao qual poderia, talvez com vantagem, ficar o Gabinete de Documentação Científica Colonial. Convinha encarar as relações entre o Museu, a Junta das Missões e o trabalho em África. (...) A ideia de um Instituto Colonial foi ventilada por quem de direito. Esse Instituto englobaria a Escola Superior Colonial, o Instituto de Medicina Tropical, a Biblioteca do Ministério, o Museu e, possivelmente, o Arquivo Histórico Colonial» (Vieira Machado in A.G.C. 1945: 17).

$\mathrm{O}$ «Plano de investigação científica colonial» vem, assim, proporcionar uma tentativa de objectivação institucional de uma corrente de opinião relativamente estável e continuada desde a viragem do século, que perfilhava um 'colonialismo científico' e teria por identidade institucional de partida mais visível a S.G.L., aglutinando, ao correr do tempo, parte da frágil comunidade científica e académica portuguesa. Os momentos de intervenção pública desta corrente de opinião, ocorrendo em situações de afirmação da legitimidade portuguesa de ocupação colonial - quer por reacção face ao xadrez da política externa (Ultimatum, Conferência de Versalhes, Relatório Ross, II. ${ }^{a}$ Guerra Mundial), quer por decorrerem de estratégias afirmativas (Exposições Internacionais, Colonial do Porto e do Mundo Português) são de molde a informar sobre o que possam ser as 'ciências coloniais'.

Um primeiro significado da expressão, é, evidentemente, excêntrico a uma prospecção dos seus conteúdos: as 'ciências coloniais' emergem periodicamente como argumento político, em particular no âmbito da argumentação no quadro internacional do consenso estabelecido em torno da doutrina da 'ocupação efectiva'. A 'ocupação científica' emerge como um estádio de um quadro abstracto e evolutivo das relações coloniais, de acordo com o qual esta fase decorreria das duas anteriores de ocupação militar e administrativa.

Um segundo significado conota o seu exercício com uma prática colonial: a prática defendida pela S.G.L., de acordo com a qual a aç̧ão colonial 
dependeria de um conhecimento prévio do meio físico e humano sob intervenção, com vista à sua maximização quer em termos económicos quer em termos, dele decorrentes, do bem estar das populações em presença.

Um terceiro significado da expressão é especificamente de conteúdo reportando-se a formas de conhecimento científico cujo objecto é geograficamente localizado nos territórios sob ocupação colonial. Desta definição consensual - que faria, por hipótese, da Botânica de Angola uma botânica colonial - emerge uma distinção entre o que pode, tentativamente, classificar-se por um grupo de 'pragmáticos' e um grupo de 'académicos': para os primeiros, as ciências coloniais são corpus de conhecimento aplicável, com retorno a curto prazo na administração, na política, na educação, na medicina e na economia coloniais; para os segundos tal corpus é indissociável do conhecimento 'puro', de lenta acumulação, resultante de investimento económico e humano continuado e estrutural, com retorno a médio ou longo prazo. Para os segundos, a Botânica de Angola seria, antes do mais, Botânica, tal como a Medicina Tropical seria, acima de tudo medicina, apesar de lidar com nosologias e terapias de ocorrência privilegiada nos trópicos.

Esta divisão que aqui se propõe é necessária para a compreensão dos projectos e práticas coloniais conotadas com a 'ocupação cientifica' das colónias. Entre o primeiro grupo, esta ocupação é susceptível de cooptar - enquanto esforço exercido no campo político - uma série de agentes coloniais de formação técnica ou superior, para o campo das práticas de recolha e tratamento de informação. Classicamente, administradores, funcionários, militares ou missionários, que à sua formação específica acrescentam a competência - nada despicienda - de se encontrarem 'no terreno', são alvos privilegiados deste recrutamento para a actividade científica, pelo menos, num dos elos da complexa cadeia do trabalho científico.

146 Noutra perspectiva, esta 'ciência de amadores' não é menos do que perniciosa, porque ao criar a ilusão de um corpo social dedicado ao trabalho científico, impede, por essa via, o desenvolvimento de um corpo social especializado, a sedimentação institucional do conhecimento científico, e a criação social do valor do conhecimento. Na proposta de reformulação da J.M.G.I.C., são, de facto ambos que perdem: os segundos porque o seu plano político é transversal à oposição metrópole / colónias, implicando o investimento na educação e o desenvolvimento coordenado dos vários graus de ensino, como complemento necessário de um investimento social na 
investigação científica. Perdem também os primeiros porque às estruturas de coordenação e rentabilização das existências no terreno que propõem se configura um organismo inoperante. Nas respectivas declarações de voto ao Conselho Imperial, Vicente Ferreira - que na interpretação sugerida se fará alinhar pelos 'académicos' (com Celestino da Costa, Luís de Pina, Gonçalo Santa-Rita, Gonçalves Pereira, Júlio Henriques e, naturalmente, Luiz Carrisso, para referir apenas os mais notórios) - ou Bacellar Bebiano, alinhando, enquanto agente do Governo, pelos 'pragmáticos', são inteiramente explícitos quanto à laboração em erro que entendem ser a reformulação da Junta que será aprovada. Vicente Ferreira:

«1. Rejeitei, na generalidade, o Plano de Investigação Científica Colonial e, entretanto, aplaudi a doutrina exposta no seu relatório, pelo Sr. Presidente da Junta das Missões Geográficas e de Investigações Coloniais. É que, no relatório, o seu ilustre autor reconhece o atraso - para não dizer 'carência total' - de conhecimentos científicos dos nossos territórios ultramarinos, demonstra a necessidade de os promover e aponta, como homem de ciência que é - os meios naturais e eficazes de os conseguir com os nossos recursos e em tão breve prazo quanto a própria natureza da investigação científica o consente, mas, ao passar do enunciado dos princípios às aplicações, porque teve em vista tudo subordinar aos cânones da administração pública, não propôs, como seria de esperar, um colégio de investigadores científicos mas arquitectou um quadro de funcionários de administração colonial adstritos para estudos científicos» (Ferreira in A.G.C. 1945: 125).

Nas restantes dez seç̧ões (de um total de onze) em que a sua declaração de voto se expressa, o tom de decepção com a pretensa reforma da Junta mantém-se, focando a submissão do trabalho científico a uma lógica burocrática como constituindo o problema central de que decorre todo o equívoco da reforma. Para o declarante, a investigação científica exige um tipo de socialidade que não é solúvel por decreto, na medida em que exige «liberdade de acção que, é, neste caso, a verdadeira liberdade de pensar» (idem: 126), de que decorre uma hierarquia própria que resulta «do valor e extensão dos próprios conhecimentos científicos: a dos mestres e dos discípulos; a do investigador e dos seus auxiliares» (idem). Consequente- 
mente o trabalho científico é incompatível com a organização burocrática (cf. idem).

«Um colégio de investigadores dotado da necessária independência poderá oferecer à Ciência e ao País resultados utilíssimos para a economia ou para a administração; uma Repartição de sábios pouco mais dará que ofícios, rivalidades, queixas, sindicâncias, e - na melhor das hipóteses - manipulações mais ou menos utilizáveis, de resultados científicos já velhos e relhos.

O projecto do Plano...(...) cria uma organização de tipo administrativo, um "serviço" com os seus quadros, hierarquias, regras de recrutamento, de promoção e de transferência, equiparações ou subordinações a outros funcionários ou serviços, limites de vencimento, etc.; em suma, uma organização burocrática da investigação científica.

Não considero de aceitar» (idem: 127, itálicos no original).

Vicente Ferreira atribui a dois constrangimentos o falhanço do projecto, sublinhando que ele não faz justiça às competências ou intenções do seu relator. A obrigatoriedade de dar continuidade à Junta, por um lado e a obrigatoriedade de limitar os custos da investigação, por outro, são definidos como 'os carrascos' reais do projecto. É, por ambos, reconhecido o facto de carecer a Junta de cientistas e auxiliares suficientes, assim como carece de financiamento mínimo. A esse propósito, de resto, elogia a argumentação comparativa, baseada numa detalhada informação sobre estruturas congéneres na Europa (cf. idem: 128). Mas prossegue:

«Parece ao signatário, entretanto, que a experiência alheia deveria corrigir, neste ponto, as nossas próprias inclinações para as poupanças inconvenientes, e que, por outro lado, as brilhantes demonstrações práticas que resultam dos trabalhos dos italianos na África Oriental, dos belgas no Congo, e dos franceses em Marrocos, nos deviam incitar ao estudo científico dos territórios e populações das nossas colónias, para sobre ele assentar não só a exploração económica das suas riquezas potenciais, mas a própria política colonial portuguesa lato sensu. Isto sem falar no prestígio, que nos incumbe defender, de mais antiga nação colonial, acusada - com certa justiça - de se encontrar, no fim de 400 anos de ocupação, mais atrasada 
no conhecimento do que lhe pertence do que as nações chegadas a África nas últimas décadas.

$\mathrm{Na}$ opinião do signatário, ou se afastam da nossa administração ultramarina as duas preocupações acima apontadas, ou ver-nos-emos, em breve, em posição desairosa perante os que, das nossas próprias colónias mais sabem já do que nós» (idem-128-129).

A este propósito distingue um conhecimento aplicado - apenas susceptível de desenvolvimento na colónia, implicando sobretudo técnicos e institutos dedicados a problemas específicos de cada colónia - de um conhecimento válido por si mesmo, necessariamente independente e acima dos problemas específicos de cada colónia. Em conformidade com esta distinção propõe:

"1. Q Que a investigação científica, aplicada ao complexo dos conhecimentos relativos às colónias, não deve limitar-se à geografia e às ciências naturais, porquanto aos fins gerais da Ciência e das suas aplicações à administração colonial também interessam - e em grau elevado - as ciências morais e políticas e as ciências aplicadas às técnicas;

2. ${ }^{a}$ Que não a um corpo de funcionários - embora também sejam homens de ciência - mas a um colégio de professores e peritos de tão variados ramos de conhecimento quanto possível, se deve confiar o encargo de promover e orientar a investigação científica respeitante às colónias; mais precisamente aos nossos professores universitários, aos cientistas portugueses em geral, aos nossos técnicos, aos chefes da administração colonial e aos próprios capitães da indústria deve incumbir o encargo daquela orientação" (idem: 129, itálicos no original).

Vicente Ferreira, vencido na votação na generalidade, acaba por aprovar todas as emendas «tendentes a ampliar as funções da Junta e a atribuir-lhe maior independência possível em matéria científica e administrativa; a desburocratizá-la, em suma (...)» (idem: 133). A orientação expressa na sua declaração de voto - a favor da delegação técnica nas colónias de trabalho científico dedicado, e de coordenação metropolitana de trabalho científico de síntese teórica - é, em parte, uma conversão para Portugal do 
que se pratica nos Impérios centrais (i.e. Inglaterra e França, Bélgica e Holanda), mas também, provavelmente, reflexo da sua experiência como Alto Comissário de Angola entre 1923 e 1925, anos em que a actividade na Província é fecunda nestes campos: dando continuidade à política federativa de Norton de Matos, realiza-se em Luanda o I Congresso Internacional de Medicina Tropical da África Ocidental, é criado o Laboratório Central de Patologia Veterinária (em Nova Lisboa e só virá a ter edifício próprio em 194.5), são criadas 16 Missões Laicas e Angola participa na Exposição Internacional de Londres.

Já a declaração de voto de Bacellar Bebiano, que o dá também como vencido na votação, espelha um conjunto de preocupações de pormenor, de quem se bate não por um projecto global de política científica, mas pela reforma administrativa possível na configuração social e política do país. A sua preocupação resume-se a procurar garantir que a legislação preconize o que pode designar-se por uma carreira de 'investigação colonial' atractiva. Para tal ela deveria satisfazer três condições: melhor salário, ingresso no quadro comum do Império Colonial ao fim de dez anos de bom efectivo serviço e direito a aposentação (cf. Bebiano in A.G.C. 1945: 136). Registe-se que nem isso é aprovado nesta reforma da Junta.

$\Lambda$ reforma aprovada pretende ser conciliatória das duas correntes em presença na discussão havida em sede do Conselho do Império Colonial:

"Neste alto corpo consultivo foi o problema discutido com grande elevação, desde logo se definindo nele duas correntes: a que entendia dever manter-se à Junta o caracter de órgão essencialmente administrativo, embora constituído por homens de ciência, mas em número reduzido e dotado de vantagens concedidas aos funcionários [nos termos aqui propostos, a corrente personificada por Bacellar Bebiano], e a que pugnava pela sua transformação em instituto de estudos e investigação largamente aberto a quantos se interessassem pelos problemas a sue cargo e revelassem méritos bastantes para nela serem admitidos sem por isso se tornarem funcionários e menos ainda burocratas [a corrente Vicente Ferreira].

Do choque das duas correntes saiu uma solução conciliadora, que foi a adoptada pelo Governo e se procura consagrar no presente diploma” (D.L. 35.395 de 1945, in A.G.C. 1945: 188). 
$\mathrm{O}$ art. ${ }^{\circ} 200^{\circ}$ do Capítulo III. ${ }^{\circ}$ referente às competências da Junta, especifica que lhe cabe organizar o Museu Colonial Português; o art. ${ }^{\circ} 24 .^{\circ}$ do mesmo capítulo indica o dever de manter a estreita colaboração com os museus de história natural das colónias. A não concretização de qualquer destes objectivos é um indício substantivo do que valeu esta reforma. De resto, isso mesmo é constatado cinco anos mais tarde aquando do Colóquio sobre Problemas de Investigação Científica Colonial, promovido pela Junta reformada. Orlando Ribeiro:

«Em todo o caso não existe entre nós tradição de investigação científica nessas matérias [de investigação científica tropical]. Para haver tradição era necessário que houvesse continuidade e escola; nem-uma nem outra coisa se verificou no desenvolvimento dos trabalhos episódicos que, há 4 séculos, os Portugueses vêm realizando nos seus territórios coloniais. (...) Portanto, quando no fim do séc. XIX, duma maneira sistemática, com intervenção dos organismos do Estado e o interesse das escolas se retomou o interesse científico das nossas colónias, dum modo geral, os diferentes ramos de investigação vão entroncar em raízes estranhas e não numa tradição nacional, que nunca chegara a consolidar-se. Assim, a tradição científica nacional é uma dessas flores de retórica, vulgares nos nossos discursos e nos nossos escritos, um destes lugares comuns com que nos consolamos do atraso actual, um facto que devia constituir motivo de redobrada responsabilidade e sobre o qual muitas vezes adormecemos, procurando iludir-nos e atenuar com ele as graves deficiências do reconhecimento actual dos territórios que nos pertencem» (Ribeiro 1950: 4).

O geógrafo prossegue, explicando que a questão das investigações coloniais, constitui apenas:

«um caso particular no panorama da investigação científica portuguesa. Os métodos, o espírito, as orientações de trabalho, são essencialmente os mesmos, quer nos ocupemos de temas científicos das nossas colónias, quer nos ocupemos de temas científicos da metrópole» (idem). 
No essencial, de facto, as suas propostas retomam os temas analisados na declaração de voto de Vicente Ferreira, que o orador conhece e cita. Decorrente desta concordância, Orlando Ribeiro procede à elaboração de um diagnóstico assaz negativo, preocupando-se com a rentabilização dos recursos materiais e humanos disponíveis, disponibilidade essa que é configurada a uma escala internacional:

«(...) cada país, se por um lado tem o dever de contribuir para o reconhecimento dos territórios que lhe pertencem pelos seus homens de estudo, tem por outro a obrigação de trazer uma contribuição nacional para os problemas gerais da ciência. E se as divisões políticas possuem para muitas ciências, na Europa, um valor convencional e arbitrário, com mais razão ainda nas colónias, onde quase nunca separam coisa alguma e nem sequer constituem limites de factos humanos, como é o caso da Europa; por isso se devem procurar não apenas desenvolver não apenas os estudos regionais desta ou daquela colónia, mas o dos grandes conjuntos naturais que as prolongam ou as enquadram» (idem: 7).

A proposta implica, nestes termos, deslocar o carácter nacional da produção científica para o contexto internacional, evitando 'uma ciência portuguesa' e promovendo 'uma contribuição portuguesa' para a ciência, com consequências essenciais à institucionalização do trabalho científico: por um lado em termos de informação, encarada como disponível a uma escala global; em termos da circulação das ideias, práticas ou métodos que sairia favorecida por um convívio científico com colegas estrangeiros e pela publicação dos trabalhos em línguas mais acessíveis; finalmente, em termos da qualidade, uma vez que a calibração dos resultados pelo mercado internacional tenderia a excluir «o amadorismo, o trabalho prematuro e os métodos antiquados ainda em uso» (idem). Para tal, é necessário proceder a adaptações institucionais, de acordo com um organigrama federativo que transformasse parte dos serviços existentes localizados na metrópole, em serviços de investigação próprios a cada colónia, subordinados - seguindo o exemplo dos Serviços de Meteorologia - a um organismo central. Esse organismo encarregar-se-ia de centralizar as publicações, fornecendo uma imagem pública de fácil identificação e passível de fiscalização exterior uma vez que nelas se daria conta do trabalho desenvolvido. 
$\Lambda$ alocução retoma a incompatibilidade entre a ciência e a burocracia para reclamar um meio de trabalho livre de horários, contabilidades, burocracias, etc. e acrescenta:

«Claro que a investigação pode e deve também servir fins práticos; quanto melhor for o conhecimento de História Natural que se tenha duma região, tanto mais firme será o delineamento do seu desenvolvimento económico. A Geografia e a Etnografia podem fornecer à Administração e à política colonial, bases muito mais sólidas. Mas o móbil principal dos homens de Ciência não é, de modo nenhum, trazer resultados úteis, mas satisfazer as curiosidades pessoais, a sua necessidade de conhecer e o seu prazer de pesquisar» (idem: 11, itálicos no original).

É do cruzamento deste tipo de preocupações manifestas em sede de instituições do governo, com a pressão política sofrida por Portugal no pósguerra mercê da adopção de uma política de autonomização progressiva dos territórios coloniais por parte das potências europeias que, na sequência da reforma administrativa de 1951, a antiga Comissão de Cartografia do Ministério das Colónias, (de 1936 em diante Junta das Missões Geográficas e Investigações Coloniais), assume, com a designação de Junta das Investigações do Ultramar, uma estrutura de coordenação da investigação colonial praticada em diversas instituições, passando, por esta via, a corporizar uma 'ocupação científica do ultramar português'. Nesse âmbito, vão sendo criados ou reformulados, ao longo da década de cinquenta, oito diferentes estruturas de gestão do conhecimento científico. São eles: $1{ }^{\text {os }}$ Centros de Botânica, de Estudos Políticos e Sociais, de Estudos de Etnologia do Ultramar, de Estudos Históricos Ultramarinos, de Investigação das Ferrugens do Cafeeiro, de Documentação Científica Ultramarina, de Geografia do Ultramar, de Zoologia; 2. os Agrupamentos - Científico de Estudos Ultramarinos, Científico de Preparação de Geógrafos para o Ultramar Português, Científico de Estudos de Geologia, Científico de Farmacognósia para o Estudo das Plantas Medicinais do Ultramar, Científico Anexo ao Laboratório de Engenharia Civil; 3. ${ }^{\text {os }}$ Núcleos - de Estudos das Oleaginosas do Ultramar Português, de Estudos Radioisótopos; 4. as Secções - de Estudos de Entomologia Aplicada, de Cartografia Antiga; 5. ${ }^{\text {os }}$ Laboratórios - de Histiologia e Tecnologia de Madeiras, de Técnicas Físico-Químicas 
Aplicadas à Mineralogia e Petrologia, de estudos Petrológicos e Paleontológicos do Ultramar; $6{ }^{\text {os }}$ Institutos - de Investigação Científica de Angola, de Investigação Científica de Moçambique (ambos criados em 1955); 7. as Brigadas - de Estudos Agronómicos para Angola, de Estudos Agronómicos para Cabo Verde, de Estudos Agronómicos para a Guiné, de Estudos Agronómicos para o Estado da Índia, de Estudos Agronómicos para S.Tomé e Príncipe, de Estudos Agronómicos para Timor (todas elas em colaboração com a Junta de Exportações do Café), de Estudos da Defesa Fistossanitária dos Produtos Ultramarinos, Hidrográfica para o estado da Índia; 8. As Missões - de Biologia Marítima (Navio Oceanográfico Baldaque da Silva), de Estudos Apícolas no Ultramar Português, para o Estudo da Atracção das Grandes Cidades e Bem-Estar Rural no Ultramar Português, de Estudos das Minorias Étnicas do Ultramar Português, de Estudos dos Movimentos Associativos em África, Científica de S.Tomé (Porto), Hidrográfica do Arquipélago de Cabo Verde, Geo-Hidrográfica da Guiné, Hidrográfica de Angola e S.Tomé, Geográfica de Angola, de Pedologia de Angola (Instituto Superior de Agronomia), Botânica de Angola e Moçambique, Geográfica de Timor, Geográfica de Moçambique, Hidrográfica de Moçambique, de Fotogrametria Aérea de Moçambique, Zoológica de Moçambique, Antropológica e Etnológica de Moçambique, de Estudo do Habitat Nativo da Guiné e de Estudo do Habitat Nativo de Timor (cf. Garcia da Orta 1958: 334 e seguintes).

Notar-se-á, para os casos de Angola e Moçambique, que o tempo de vida dos Institutos criados não chega a vinte anos e especifique-se que, nos restantes casos, se trata de proporcionar uma cobertura administrativa sob o âmbito da investigação, agora ultramarina, a um conjunto de instituições e agentes do trabalho científico já existentes e em actividade. Dito de outra forma, a reforma da Junta nos anos cinquenta, largamente baseada nas alterações introduzidas pelo diploma de 1945 e que foram sendo aplicadas ao correr do tempo, significa pouco mais que a conferência de visibilidade pública e unidade institucional a uma prática científica que lhe é anterior e cujo peso no processo colonial gerido pelo Estado é, na prática, negligenciável. A título de exemplo, constate-se que o Agrupamento Científico de Estudos das Províncias Ultramarinas criado em 1953, não passa de uma designação do grupo de académicos da Faculdade de Ciências da Universidade de Coimbra, cujo trabalho se relaciona com questões ultramarinas. É, de resto, neste âmbito que o Museu Antropológico agrega o qualificati- 
vo Ultramarino, sem que qualquer alteração substantiva se processe quer a nível orgânico quer institucional, quer, ainda, prático. O mesmo pode ser dito a propósito de outros Agrupamentos, Centros, Laboratórios, Brigadas ou Missões, que incorporam, para além de institutos, laboratórios, museus ou pessoal universitário, elementos ou equipamentos sob tutela do Exército, Marinha, ou Governos Provinciais. Entre quadros do Exército, do Governo e das Universidades, dividido pelas várias unidades orgânicas da Junta, e integrando, frequentemente, várias unidades ao mesmo tempo, o contingente de pessoal - para todos os efeitos - científico, é pouco superior aos duzentos indivíduos. Prolonga-se, nos anos 50, o quadro constatado por Ramos do Ó para as décadas anteriores, segundo o qual «Não parece correcto falar (...) de comunidade científica nem das suas práticas como integrantes da força produtiva» (1999: 68).

Neste contexto, a trágica morte de Luiz Carrisso no Sul de Angola em 1937, no decurso da terceira Missão Botânica, terá contribuído para um maior enfraquecimento de uma já débil corrente - política e científica que terá sido minoritária no Império Colonial Português. A subalternidade da ciência e a concomitante desvalorização dos seus agentes sociais, terá constituído - numa perspectiva comparativa com a de outros Impérios coloniais e por razões totalmente alheias àquelas que são comummente invocadas - uma das mais marcantes especificidades do chamado 'colonialismo português'.

\section{Referências bibliográficas}

ACCialuıoli, Margarida - Exposições do Estado Novo 1934-1940. Lisboa : Livros Horizonte, 1998.

Agência Geral das Colónias - Ocupação Cientifica do Ultramar Português, Plano elaborado pela Junta das Missões Geográficas e Investigações Coloniais e Parecer do Conselho do Império Colonial. Lisboa, 1945.

Azevedo, José Fraga de - O Instituto de Medicina Tropical. Anais do Instituto de Medicina Tropical, vol. 15, Supl. 1 (1958), p: 9-309.

Carrisso, Luiz - A Missão Académica a Angola, os seus objectivos e resultados.

Boletim da Agência Geral das Colónias. Ano VIII, n. ${ }^{\circ} 81$ (1932), p. 44-64. 
Catroga, Fernando - Ritualizações da história. Torgal, L. R. ; Mendes, J. M. ; Catroga, F. (org.), História da História em Portugal. Sécs. XIX-XX, da Historiografia à memória histórica, vol. II, ed. Temas e Debates, 1998, p. 221-364.

Chaves, Luís - Museu Etnográfico do Império Português. Trabalhos do $10^{\circ}$ Congresso Nacional de Antropologia Colonial. Porto, 1934, p. 28-45.

Costa, Celestino - A investigação Científica Colonial. Congresso do Mundo Português: publicações. Vol. XIV, Tomo 1. ${ }^{\circ}$, I Seç̧ão. Lisboa : Com. Executiva dos Centenários, 1940, p. 83-98.

Dias, Nélia - Le Musée Ethnographique du Trocadéro (1878-1908), Anthropologie et Muséologie en France. Paris : éditions du C.N.R.S., 1991.

PAÇO, Afonso - Da necessidade da criação do Museu de Etnografia. Trabalhos do $1 .^{\circ}$ Congresso Nacional de Antropologia Colonial. Porto, 1934, p. 23-27.

Paulo, Heloísa - 'Vida e Arte do Povo Português' Uma visão da sociedade segundo a propaganda oficial do Estado Novo. Revista de História das Ideias, vol. 16 (1994) p. 105-134.

Ramos, Rui - A Segunda Fundação (1820-1926), vol. vi de Mattoso, José (dir.) História de Portugal. Lisboa : Círculo de Leitores, 1994.

Ramos do Ó, Jorge - Os anos de Ferro - o dispositivo cultural durante a 'Política do Espírito’ 1933-1949. Lisboa : Ed. Estampa, 1999.

Ribeiro, Orlando - Problemas da Investigação Científica Colonial (Colóquio realizado na Junta de Investigações Coloniais em 30 de Dezembro de 1949). Lisboa : Ministério das Colónias, Junta de Investigações Coloniais, 1950, p. 1-23.

Rodrigues, João F. - Plano de um organismo e orientação da investigação científica nas Colónias. Congresso do Mundo Português: publicações. Vol. XIV, Tomo 1., I Seç̧ão. Lisboa : Com. Executiva dos Centenários, 1940, p. 63-80.

SANTA Rita, José Gonçalo - A Investigação Portuguesa nos últimos 100 anos. Congresso do Mundo Português: publicações. Vol. XIV, Tomo $1 .^{\circ}$, I Secção. Lisboa : Com. Executiva dos Centenários, 1940, p. 13-29.

156 Santos Júnior, Joaquim R. - Museu Colonial (Fora do programa). Congresso do Mundo Português : publicações. Vol. XIV, Tomo 1. ${ }^{\circ}$ I Secção. Lisboa : Com. Executiva dos Centenários, 1940, p. 101-109.

Thomaz, Omar Ribeiro - Ecos do Atlântico Sul: Representações sobre o terceiro Império Português. São Paulo : Universidade de São Paulo, 1997. Tese de Doutoramento. 



\section{Série}

\section{Documentos}

Imprensa da Universidade de Coimbra

Coimbra University Press

2005

- U

C - 